Volume 4 Nomor 1, Januari-Juni 2020: hlm. 15-28.

Fakultas Hukum, Universitas Lampung,

Bandar Lampung, Lampung, Indonesia.

E-ISSN: 2598-3105 P-ISSN: 2723-2581

http://jurnal.fh.unila.ac.id/index.php/cepalo

\title{
BENTUK HUKUM PERUSAHAAN PERSEKUTUAN DI INDONESIA DAN PERBANDINGANNYA DI MALAYSIA
}

\author{
PARTNERSHIP LEGAL FORM IN INDONESIA AND ITS COMPARASION IN \\ MALAYSIA
}

\section{Rizha Claudilla Putri}

Fakultas Hukum Universitas Indonesia, Email: rizhaclaudillaputri@yahoo.com

Submitted: February 11, 2020; Reviewed: February 24, 2020; Accepted: March 9, 2020

DOI: 10.25041/cepalo.v4no1.1913

\begin{abstract}
Abstrak
Perusahaan dapat dibedakan atas perusahaan badan hukum dan perusahaan bukan badan hukum. Di Indonesia, Perusahaan badan hukum dapat berbentuk Perseroan Terbatas (PT), Yayasan dan Koperasi. Sedangkan perusahaan bukan badan hukum dapat berupa Firma (Fa) dan Persekutuan Komanditer atau Comanditaire Vennootschap (CV). Peraturan mengenai bentuk perusahaan persekutuan, firma dan CV terdapat di dalam KUHPer dan KUHD. Sama halnya seperti di Indonesia, bentuk hukum suatu perusahaan Malaysia dapat dikenal dengan beberapa bentuk business entitiy, seperti Sole Proprietorship, Partnership, Limited Liability Partnership (LLP), Private Limited Company/SendirianBerhad (Sdn Bhd), dan Public Limited Company/Berhad (Bhd). Beberapa Business Entity yang ada di Malaysia memiliki kemiripan dengan jenis badan usaha yang ada di Indonesia, seperti Partnership atau Perusahaan Persekutuan. Terdapat pula perbedaan antara bentuk dan peraturan yang mengatur perusahaan persekutuan Indonesia dengan perusahaan persekutuan Malaysia. Undang-Undang yang digunakan pun berbeda bagi kedua negara, Partnership diatur dalam Partnership Act 1961 sedangkan untuk Limited Liability Partnership diatur dalam Limited Liability Act 2012. Penelitian hukum ini menggunakan metode penelitian normatif dengan pendekatan komparatif. Data yang digunakan adalah data sekunder yang didapat dari bahan hukum primer, sekunder dan tersier. Pengumpulan data dilakukan melalui studi kepustakaan dan dokumen serta diolah dengan melakukan seleksi data secara sistematis untuk mendapatkan gambaran umum dari hasil penelitian. Hasil penelitian menunjukkan bahwa dalam Partnership mengatur mengenai perusahaan secara tradisional dengan ingin mendapatkan laba atau keuntungan. Sedangkan di dalam LLP menggabungkan antara partnership dan company. Perbedaan bentuk hukum perusahaan persekutuan antara Indonesia dan Malaysia ini juga jelas terlihat jika dilihat dari aturan pada masing-masing negara dimana Indonesia tidak mempunyai undang-undang khusus mengenai bentuk hukum persekutuan ini. Dengan demikian, pemerintah hendaknya membuat sebuah undang-undang yang mengatur mengenai bentuk usaha persekutuan lebih khusus dalam peraturan yang berbeda agar dapat mudah dipahami oleh pelaku usaha seperti peraturan yang berlaku di negara Malaysia.
\end{abstract}

Kata Kunci: Liability, Persekutuan, Perusahaan. 


\section{Abstract}

Company can be distinguished by its entity, such as legal entity and non-legal entity. In Indonesia, a legal entity company can be a PT and cooperative. Whereas, a non-legal entity company can be in a form of a Firm (Fa) or Comanditaire Vennootschap (CV). The rules about the Partnership can be found in KUHPerdata and KUHD. Just like in Indonesia, the legal form of a Malaysian company known by the several forms of business entity, such as seperti Sole Proprietorship, Partnership, Limited Liability Partnership (LLP), Private Limited Company/SendirianBerhad (Sdn Bhd), dan Public Limited Company/Berhad (Bhd). Partnership in Malaysia has a lot of similarities like in Indonesia. The similarities can be seen from each country's article. Also LLP can be said as a CV in Indonesia, where it found and regulated in Partnership Act 2012 Malaysia. There are also the difference about Partnership's legal forms and regulation between Indonesia and Malaysia. The laws that they used are different, the Partnership is regulated in 1961 Partnership Act meanwhile for the Limited Liability Partnership (LLP) is regulated in 2012 Limited Liability Act. Problems: How is the Partnership Legal Form that applies in Malaysia? How is the comparison between Partnership and Limited Liability Partnership (LLP) in Malaysia? And how is the Partnership's comparison in Malaysia and Indonesia based on its regulation? This legal research uses a normative research method with a comperative approach. The data used are secondary data obtained from primary, secondary and tertiary legal material. The data collected through the study of literature and documensts and processed systematically to get a general picture of the results of the research. The result showed that Partnership regulates the company traditionally by wanting to make a profit. While in LLP, this is a little bit different because LLP itself a combination between a partnership and a company. The laws used are also different. The Partnership is regulated in the 1961 Partnership Act and the LLP is regulated in the 2012 Limited Liability Act. The difference about the legal form between these country can be seen from the regulation in each country, where Indonesia does not have a specific laws regarding this bussiness entity. Thus, the government should make a specific laws so it can be easily understood by business actors like the one in Malaysia.

Keywords: Company, Liability, Partnership.

\section{A. Pendahuluan}

Perusahaan menurut Molengraaff adalah keseluruhan perbuatan yang dilakukan secara terus menerus, bertindak keluar untuk memperoleh penghasilan, dengan cara memperdagangan atau menyerahkan barang atau mengadakan perjanjian perdagangan. ${ }^{1}$ Polak menjelaskan bahwa suatu usaha untuk dapat dimasukkan dalam pengertian perusahaan harus mengadakan pembukuan, yaitu perhitungan mengenai laba dan rugi, Sumber hukum dan ruang lingkup dari Hukum Perusahaan ini ada didalam Kitab Undang-Undang Hukum Perdata (KUHPerdata) dan Kitab Undang-Undang Hukum Dagang (KUHD). ${ }^{2}$

Jenis perusahaan berdasarkan jumlah pemiliknya dapat diklasifikasikan menjadi perusahaan perseorangan dan perusahaan persekutuan atau kerjasama. Perusahaan perseorangan didirikan dan dimiliki oleh satu orang pengusaha, sedangkan beberapa orang

\footnotetext{
${ }^{1}$ Abdulkadir Muhammad, Hukum Perusahaan Indonesia (Bandung: Citra Aditya Bakti, 2002), 7.

2 Agus Budianto, "PEMBAHARUAN KITAB HUKUM DAGANG INDONESIA : ANTARA KODIFIKASI, KOMPILASI DAN KONSOLIDASI,” Jurnal Ilmu Syari'ah Dan Hukum “Asy-Syir'ah” 47, no. 2 (2013): 703$725,704$.
} 
pengusaha yang bekerja sama dalam satu persekutuan (maatschap, partnership). ${ }^{3}$ Jenis perusahaan dari status hukumnya dapat dibedakan atas perusahaan badan hukum dan perusahaan bukan badan hukum. Perusahaan badan hukum ada yang dimiliki oleh pihak swasta seperti Perseroan Terbatas (PT) dan koperasi, serta ada pula yang dimiliki oleh negara seperti Perusahaan Umum. ${ }^{4}$ Di dalam KUHD, terdapat dua golongan bentuk perusahaan atau bentuk badan usaha yaitu persekutuan dengan firma dan Persekutuan Komanditer atau Commanditaire Vennootschap disingkat $\mathrm{CV} .{ }^{5}$

Selanjutnya, pengertian mengenai Persekutuan Perdata diatur dalam pasal 1618 KUH perdata, yaitu suatu persetujuan antara dua orang atau lebih yang berjanji untuk memasukkan sesuatu ke dalam perseroan itu dengan maksud supaya keuntungan yang diperoleh dari perseroan itu dibagi diantara mereka. ${ }^{6}$ Dalam pasal 16 KUHD, dijelaskan bahwa Perseroan Firma adalah suatu perseroan yang didirikan untuk melakukan suatu usaha di bawah satu nama bersama. ${ }^{7}$ Pada dasarnya perusahaan persekutuan ${ }^{8}$ adalah perusahaan yang dimiliki oleh dua orang atau lebih yang disebut sekutu. Maka, dalam bentuk usaha tersebut terdapat aturan hukum yang mengatur hubungan hukum diantara para sekutu yang dikenal dengan aspek hukum internal dan aturan yang mengatur hubungan hukum antara para sekutu dengan pihak ketiga atau aspek hukum eksternal. ${ }^{9} \mathrm{CV}$ adalah suatu perusahaan yang didirikan oleh satu atau beberapa orang secara tanggung menanggung, bertanggung jawab secara seluruhnya dengan satu orang atau lebih sebagai pelepas uang dan diatur di dalam KUHD. ${ }^{10} \mathrm{CV}$ juga dijelaskan sebagai persekutuan dengan Firma sebagai suatu Maatschap, sehingga ketentuan di atas berlaku pula untuk bentuk perdata khusus, yaitu Firma dan CV, dan tetap dianggap sebagai bukan badan hukum. ${ }^{11}$ Dengan demikian, dapat dilihat jelas bahwa CV adalah juga Firma, dan Firma adalah juga Maatschap. Pada suatu Persekutuan Komanditer atau limited partnership, terdapat satu atau beberapa orang sebagai sekutu komanditer. ${ }^{12}$ Sekutu komanditer hanya menyerahkan uang, barang atau tenaga kepada CV sebagai pemasukan dan mereka tidak turut campur tangan dalam pengurusan dan penguasaan dalam persekutuan. Status hukum seorang sekutu komanditer dapat disamakan dengan seorang yang meminjamkan atau menanamkan modal pada suatu perusahaan dan diharapkan dari

\footnotetext{
${ }^{3}$ Julius Caesar Transon Simorangkir, "TANGGUNG JAWAB SEKUTU MAATSCHAP TERHADAP PIHAK KE 3 DALAM SUATU PERJANJIAN KONSORSIUM TERKAIT BUBARNYA MAATSCHAP ATAS KEHENDAK PARA SEKUTU (KASUS PERJANJIAN KONSORSIUM ANTARA PT AGRO BINTANG DHARMA NUSANTARA DENGAN PEMERINTAH DAERAH BALIKPAPAN, BONTANG," Fiat Justisia: Jurnal Ilmu Hukum 9, no. 2 (2016): 233-255, 235, DOI: 10.25041/fiatjustisia.v9no2.599.

${ }^{4}$ Rudhi Prasetya, Maatschap, Firma, dan Persekutuan Komanditer (Bandung: Citra Aditya Bakti, 2002 ), 21.

${ }^{5}$ Nindyo Pramono, Perbandingan Perseron Terbatas di Beberapa Negara (Jakarta: Pusat Penelitian dan Pengembangan Sistem Hukum Nasional Badan Pembinaan Hukum Nasional Kementerian Hukum dan Hak Asasi Manusia R.I, 2012), 1.

${ }^{6}$ KUHD Pasal 1618.

${ }^{7}$ Pasal 16 KUHD.

${ }^{8}$ Ina Zakhina, Rachmad Safa'at, and Istislam, "SUMMARY FOR POLICYMAKErs," ed. Intergovernmental Panel on Climate Change, Climate Change 2013 - The Physical Science Basis 8, no. 9 (2016): 1-30, DOI: 10.1017/CBO9781107415324.004.

${ }^{9}$ Yetty Komalasari Dewi, Hukum Persekutuan di Indonesia Teori dan Kasus (Depok: Badan Penerbit Fakultas Hukum Universitas Indonesia, 2017), 14.

${ }^{10}$ Marhamah Edy Susanto, Summary For Policymakers, ” in Climate Change 2013 - The Physical Science Basis, ed. Intergovernmental Panel on Climate Change, volume 53 (Cambridge: Cambridge University Press, 2019), 130, DOI: 10.1017/CBO9781107415324.004.

${ }^{11}$ HMN. Purwosutjipto, Pengertian Pokok Hukum Dagang Indonesia: Bentuk-Bentuk Perusahaan (Jakarta: Djambatan, 1987), 8.

${ }^{12}$ Muhammad Ramadhan and Yunial Laily, “ANALISIS HUKUM PERJANJIAN KERJA SAMA INVESTASI ANTARA PERSEKUTUAN KOMANDITER DAN INVESTOR ASING MENURUT HUKUM INVESTASI DI INDONESIA,” Jurnal Ilmu Hukum 5, no. 1 (2018): 771-780, 774, DOI: 10.5281/zenodo.1684252.
} 
penanaman modal itu adalah hasil keuntungan dari modal yang dipinjamkan atau diinvestasikan tersebut. ${ }^{13}$

Seperti di Indonesia, pembangunan negara Malaysia pun di tunjang oleh berbagai perusahaan yang melakukan kegiatan usahanya. Apabila merujuk pada sistem hukum Common Law yang dianut di negara tersebut, mereka mengenal beberapa bentuk organisasi bisnis atau business entitiy, diantaranya adalah: ${ }^{14}$ Sole Proprietorship, adalah suatu perusahaan yang hanya dimiliki oleh satu orang dimana segala pengendalian dan pengambilan keputusan terhadap jalannya suatu perusahaan berada di tangan pemilik perusahaan. Partnership, atau yang biasa disebut juga dengan persekutuan adalah suatu perusahaan yang didirikan atau dimiliki oleh 2 (dua) orang atau lebih yang disebut "sekutu". Tipe bisnis ini biasanya lebih cocok untuk perusahaan atau firma-firma profesional. Sama seperti Sole Proprietorship, hanya warga negara Malaysia saja yang dapat mendaftarkan perusahaan persekutuan ini. Limited Liability Partnership (LLP), ini adalah merupakan gabungan antara persekutuan dengan Private Limited Company. ${ }^{15}$ Jenis ini memiliki kesamaan dengan persekutuan konvensional namun dengan keuntungan seperti Private Limited Company. Private Limited Company/SendirianBerhad ( $S d n$ Bhd), ${ }^{16}$ adalah suatu perusahaan yang entitasnya terpisah dari pemegang perusahaan tersebut dimana perusahaan tersebut dapat dikatakan sebagai "legal person" yang dapat membuat kontrak atau transaksi sendiri, membayar pajak, menjual property serta menutut maupun dituntut ke pengadilan. Sdn Bhd ini dapat dikatakan sebagai Perseroan Terbatas di Indonesia dan Public Limited Company/Berhad (Bhd), ini adalah mirip dengan $S d n$ Bhd kecuali dalam halnya saham dapat ditawarkan kepada publik dalam periode tertentu. Bhd diharuskan memiliki lebih dari 50 orang anggota dan jumlah maksimumnya adalah tidak terbatas. Jenis badan usaha ini biasanya melibatkan perusahaan yang terdaftar dan diatur oleh Komisi Sekuritas Malaysia. Beberapa Business Entity $^{17}$ yang ada di Malaysia memiliki kemiripan dengan jenis badan usaha yang ada di Indonesia, seperti dalam halnya mengenai Partnership atau Perusahaan Persekutuan. Dimana berdasarkan Malaysia Partnership Act 1961 dikatakan; "Partnership is the relation which subsists between persons carrying on business in common with a view of profit". Jika dilihat pengertian tersebut memiliki kemiripan dengan maksud Persekutuan yang dimaksud dalam Pasal 1618 KUHPerdata. Juga LLP dapat dikatakan sebagai Persekutuan Komanditer atau CV jika di Indonesia, dimana dan diatur dalam Partnership Act 2012 dalam hukum Malaysia. ${ }^{18}$

Berdasarkan hal tersebut, penulis menentukan rumusan masalah yang akan dibahas dalam penelitian ini ialah bagaimanakah bentuk hukum/legal form perusahaan persekutuan yang berlaku di Malaysia? Bagaimanakah perbandingan antara Partnership dan Limited Liability Partnership (LLP) di Malaysia? Dan Bagaimanakah perbandingan bentuk hukum persekutuan di Indonesia dan Malaysia menurut Undang-Undang tiap negara?

\footnotetext{
${ }^{13}$ Ibid.

${ }^{14}$ www.paulhypepage.my/what-are-the-5-types-of-business-entity-in-malaysia/, diakses pada 20 Januari 2020.

15 Jaswadi, "PENERAPAN GOOD GOVERNANCE PADA PERUSAHAAN SKALA KECIL DAN MENENGAH NON GO PUBLIC," Journal of Research and Applications: Accounting and Management 1, no. 3 (2016): 236-248, 238, DOI: 10.18382/jraam.v1i3.39.

16 Elias G. Carayannis and Ruslan Rakhmatullin, "THE QUADRUPLE/QUINTUPLE INNOVATION HELIXES AND SMART SPECIALISATION STRATEGIES FOR SUSTAINABLE AND INCLUSIVE GROWTH IN EUROPE AND BEYOND," Journal of the Knowledge Economy 5, no. 2 (2014): 212-239, 15, DOI: $10.1007 / \mathrm{s} 13132-014-0185-8$.

${ }^{17}$ K. S. Manikandan and J. Ramachandran, "BEYOND INSTITUTIONAL VOIDS: BUSINESS GROUPS, INCOMPLETE MARKETS, AND ORGANIZATIONAL FORM," Strategic Management Journal 36, no. 4 (2015): 598-617, 260, DOI: 10.1002/smj.2226.

${ }_{18} \mathrm{Ni}$ Made Pratiwi Dharnayanti, Yohanes Usfunan, and I Made Sarjana, "HUBUNGAN HUKUM PERUSAHAAN INDUK BERBENTUK PERSEROAN TERBATAS DENGAN ANAK PERUSAHAAN BERBENTUK PERSEKUTUAN KOMANDITER," Acta Comitas 2, no. 1 (2017): 66-74, 70, DOI: 10.24843/AC.2017.v02.101.p06.
} 
Penelitian hukum ini menggunakan metode penelitian normatif dengan pendekatan komparatif. Penelitian normatif merupakan merupakan penelitian hukum tentang asas-asas hukum yang didasarkan pada peraturan perundang-undangan, teori-teori, dan konsep-konsep yang berhubungan dengan penulisan penelitian ini. Dalam penulisannya, penulis menggunakan bahan kepustakaan atau data sekunder sebagai acuan penulisan. Dalam penelitian hukum normatif, dapat digunakan pendekatan komparatif, yaitu penelitian tentang perbandingan hukum baik mengenai perbandingan sistem hukum antar negara, maupun perbandingan produk hukum dan karakter hukum antar waktu dalam satu negara. ${ }^{19}$ Data sekunder terdiri dari bahan hukum primer, yaitu bahan-bahan hukum yang mengikat yang berkaitan dengan pengaturan hukum perusahaan tersebut. Bahan hukum primer terdiri dari Kitab Undang-Undang Hukum Perdata (KUH Perdata), Kitab Undang-Undang Hukum Dagang (KUHD), Partnership Act of Malaysia 1961, dan Partnership Act of Malaysia 2012. Bahan hukum sekunder, yaitu bahan hukum yang diperoleh dari studi kepustakaan, yang terdiri dari literatur-literatur atau buku-buku ilmu pengetahuan hukum yang berkaitan dengan pokok bahasan serta bahan hukum tersier, yaitu bahan-bahan yang berguna untuk memberikan penjelasan terhadap bahan hukum primer maupun sekunder, seperti hasil penelitian, Kamus Besar Bahasa Indonesia, artikel-artikel dari internet dan bahan-bahan lain yang sifatnya karya ilmiah berkaitan dengan masalah yang akan dibahas dalam jurnal ini.

\section{B. Pembahasan}

\section{Bentuk Hukum/Legal Form Perusahaan Persekutuan Yang Berlaku di Malaysia}

Sistem hukum di Malaysia menganut sistem hukum common law. Hal tersebut membuat perbedaan yang dapat terlihat mengenai tatanan hukum yang ada di negara tersebut. Terdapat empat sumber hukum pokok di Malaysia yaitu, hukum tertulis, hukum kebiasaan, hukum islam dan hukum adat. Dilihat dari sistem hukum yang dianut oleh negara Malaysia berbeda dengan Indonesia, maka dari sistem pelaksanaan perekonomian dan aturan mengenai perusahaannya pun akan bebeda walaupun ada beberapa kemiripan diantara keduanya. ${ }^{20}$ Pembangunan perekonomian di Malaysia ditunjang oleh berbagai perusahaan dengan berbagai bentuk dan jenis badan hukumnya. Pada umumnya terdapat berbagai jenis bentuk usaha dari skala mikro, kecil dan sederhana. ${ }^{21}$ Persekutuan atau yang biasa disebut Partnership ataupun Perkongsian di Malaysia umumnya adalah jenis usaha yang dipilih oleh penguasaha kecil dan menengah bahkan oleh para profesional yang tidak diizinkan oleh badan pengawasnya masing-masing untuk mendirikan jenis bentuk usaha lain. ${ }^{22}$ Peraturan yang mengatur mengenai Partnership ini ada di dalam PartnershipAct 1961. Di dalam act ini mengatur segala hal mengenai Persekutuan secara umum dan juga firma yang termasuk di dalamnya. Perkembangan mengenai Partnership ini berdasarkan banyaknya warga negara Malaysia yang melakukan usaha. Namun, semakin berkembangnya zaman dan perekonomian, dirasakan aturan mengenai Partnership ini secara umum sudah tidak relevan dan cocok dengan beberapa bisnis yang ada khususnya secara profesional. Hal ini selanjutnya mengarah kepada terbentuknya Limited Liability Partnership (LLP) dimana pada bulan April 2008, The Companies Commission of Malaysia (CCM) mengusulkan untuk mengubah bentuk usaha di

\footnotetext{
19 Johan Nasution, Metode Penelitian Hukum (Bandung: Mandar Maju, 2008), 81.

${ }^{20} \mathrm{http}$ //syariah.uin-malang.ac.id/index.php/komunitas/blog-fakultas/entry/perbandingan-struktur-sistem-hukummalaysia-dan-indonesia, diakses pada 27 Mei 2020.

21 Zuhairah Ariff Abd Ghadas, Engku Rabiah Adawiah Engku Ali, "THE DEVELOPMENT OF PARTNERSHIP BASED STRUCTURE IN COMPARISON TO THE CONCEPT OF MUSHARAKAH (SHARIKAH) WITH SPECIAL REFERENCE TO MALAYSIA”, Journal of Islam in Asia 8, no. 2 (2012): 293315, 294-295, DOI: 10.31436/jia.v8i0.248.
} 
Malaysia. Menurut dokumen konsultatifnya, suatu bentuk usaha yang fleksibel dalam hal pembentukan, pemeliharaan dan pemutusan hubungan kerjanya, juga dinamis diperlukan untuk memungkinkan negara agar lebih kompetitif di tengah era globalisasi. ${ }^{23}$

Di dalam LLP ini, peraturan baru segera disahkan untuk menunjang segala kegiatan dan aturan mengenai LLP, yaitu adalah Partnership Act 2012. LLP ini sebenarnya masih merujuk kepada aturan mengenai Partnership itu sendiri sebagai dasar untuk melaksanakan kegiatannya dengan menggabungkannya dengan konsep company. ${ }^{24}$ Oleh karena itu, sekutu yang ada di dalam LLP terbatas dan LLP merupakan bentuk badan hukum yang terpisah dari sekutunya. Dengan demkian, manajemen di dalam LLP tidak tunduk pada prosedur manajemen yang ketat dari sebuah badan yang berbadan hukum. CCM memiliki tujuan untuk memperkenalkan LLP sebagai bentu usaha baru di Malaysia pada tahun 2009.

LLP merupakan suatu badan usaha yang tanggungjawab hukumnya terpisah dengan anggota sekutunya. LLP ini didirikan berdasarkan suatu perjanjian didirikan berdasarkan perjanjian tertulis yang telah disepakati sebelumnya antara para sekutu dan selanjutnya didaftarkan ke Kementrian Perdagangan. Semua anggota sekutu dalam LLP ini disebut sebagai agent (ejen) yang berarti semua anggota sekutu adalah sekutu aktif (semua sekutu / agent) dapat mengikat untuk dan atas nama persekutuan $(L L C)$ dalam menjalankan kegiatan usaha persekutuan, namu dalam bidang administratif salah satu anggota persekutuan (sekutu) harus ditunjuk sebagai compliance officer (pegawai pematuhan) untuk mengurus seluruh kepentingan administratif dari LLC.

Dengan adanya LLP pemerintah Malaysia mengharapkan untuk dapat meningkatkan sistem perekonomian di negara nya. Perubahan yang dilakukan dari Partnership yang tradisional menjadi LLP yang lebih modern dengan menggabungkan jenis Partnership dan company. Struktur baru LLP ini diakui sebagai badan hukum yang berbeda dengan Persekutuan atau Partnership. Jenis usaha LLP ini juga tidak hanya ada di Malaysia, melainkan di Inggris, Amerika, Singapore dan negara lainnya.

\section{Perbandingan Antara Partnership Dan Limited Liability Partnership (LLP) Di Malaysia}

Partnership dan Limited Liability Partnership (LLP $)^{25}$ merupakan satu kesatuan namun memiliki perbedaan yang cukup banyak dan dapat dilihat perbedaannya. Jika dilihat dari undang-undang yang berlaku, Partnership adalah suatu hubungan antara dua orang atau lebih yang menjalankan bisnis yang sama dengan tujuan mendapatkan suatu keuntungan (Article 1 Partnership Act 1961), sedangkan Limited Liability Partnership: Badan usaha yang tanggungjawab hukumnya terpisah dengan anggota sekutunya (Article 2 Limited Liability Partnership Act 2012). Persekutuan (Firma) diatur dalam Partnership Act 1961 dan Limited Liability Partnership: diatur dalam Partnership Act $2012^{26}$. Perbedaan yang paling mencolok antara keduanya adalah dalam LLP, anggota atau sekutu tidak secara pribadi bertanggung jawab atas hutang dan kewajiban bisnis, sedangkan Partnership, semua anggota wajib untuk hutang sejauh aset pribadi yang mereka miliki. Di dalam Partnership juga seluruh anggota bertanggung jawab untuk segala tindakan yang dilakukan selama dalam masa perjanjian

\footnotetext{
${ }^{23}$ Chan Wai Meng, et. Al., eds., "LIMITED LIABILITY PARTNERSHIP: IS MALAYSIA READY?", Proceedings of the $3^{\text {rd }}$ International Borneo Business Conference 2008, 275.

${ }^{24}$ Per Davidsson, "ENTREPRENEURIAL OPPORTUNITIES AND THE ENTREPRENEURSHIP NEXUS: A RE-CONCEPTUALIZATION,” Journal of Business Venturing 30, no. 5 (2015): 674-695, 680, https://doi.org/10.1016/j.jbusvent.2015.01.002.

${ }^{25}$ david Kelly, Ruby Hammer, and John Hendy, "PARTNERSHIP LAW," Business Law 69, no. 3 (2017): 323352, 346, https://doi.org/10.4324/9781315726205-17.

${ }^{26}$ N. A. Rahman et al., "LIMITED LIABILITY PARTNERSHIP (LLP@PLT): NEW BUSINESS VEHICLE FOR THE MALAYSIAN LEGAL AND ACCOUNTING PRIVATE PRACTICE," Pertanika Journal of Social Sciences and Humanities 23, no. 11 (2015): 211-218.
} 
persekutuan tersebut. Tetapi dalam LLP, kewajiban para anggota hanya sebatas pada kontribusi yang disepakati. ${ }^{27}$

Prinsip agensi dalam LLP juga secara signifikan berbeda dari Partnership karena sekutu dari LLP adalah agent LLP dan bukan dari sekutu lainnya. Oleh karena itu, posisi sekutu sama dengan direktur perusahaan. Untuk suatu situasi dimana sekutu bertindak tanpa otoritas, LLP tidak bertanggung jawab akan hal tersebut jika pihak luar mengetahui bahwa sekutu tersebut tidak memiliki kewenangan atapun tidak mengetahui jika dia merupakan sekutu dari LLP tersebut. ${ }^{28}$ Perlu diketahui bahwa Undang-Undangn yang mengatur LLP secara khusus menetapkan bahwa hukum yang berkaitan dengan Partnership tidak berlaku untuk LLP.

Partnership dapat berakhir apabila jangka waktu yang ditetapkan berakhir, jika terjadi pengambilaihan atau pembubaran yang dikarenakan oleh pengambilalihan dan jika dalam waktu yang tidak ditentukan, sekutu memberi pemberitahuan kepada sekutu lain atas keinginannya membubarkan persekekutuan (Article 34 Partnership Act 1961), sedangkan LLP ada tiga hal yang dapat terjadi dalam pembubarannya yaitu Winding-up, Dissolution, Striking-off yang mana dalam bahasa malaysia disebut Penggulungan, Pembubaran dan Pemotongan (Pasal 49,50,51 LLC ACT) yang mana pembubaran ini dapat dilakukan oleh:

a. Pengadilan (Mahkamah) dikarenakan melanggar ketentuan dalam Akta Syarikat (Companies Act) 1965 dan Companies (Winding-up) Rules 1972[P.U. (a) 289/1972], dan

b. Pembubaran secara sukarela dari persekutuan ( $L L C)$ apabila LLC tersebut telah menunaikan semua kewajiban atau berehenti beroperasi (tidak ada hutangnya) dapat memohon kepada lembaga berwenang (Chief Executive Officer of the commission atau dalam bahasa malaysia Ketua Pegawai Eksekutif Suruhanjaya) untuk memohon pernyataan pembubaran.

Ketiga adalah pembubaran dilakukan oleh lembaga yang berwenang/Pendaftar (Chief Executive Officer of the commission atau dalam bahasa Malaysia Ketua Pegawai Eksekutif Suruhanjaya) apabila LLC dianggap telah melanggar ketentuan LLC Act, adanya kepentingan negara LLC tidak memiliki asset lagi dan tidak beroperasi kembali). Meskipun memiliki tanggung jawab yang berbeda LLP dan Partnership memiliki kemiripan dengan LLP. LLP menyerupai Partnership dalam beberapa cara, termasuk: ${ }^{29}$

a. Penggunaan istilah "sekutu";

b. Persyaratannya minimum dua orang;

c. Fakta bahwa itu adalah asosiasi untuk memperoleh laba/keuntungan; ${ }^{30}$

d. Fakta bahwa itu adalah hubungan hukum berdasarkan suatu perjanjian. ${ }^{31}$

Keduanya juga hampir idientik dalam hal peraturan internal dan perpajakan. Dalam hal kedua business entity ini, keduanya diatur melalui perjanjian diantara sekutu atau anggota. Tidak ada konstitusi formal seperti memorandum dan anggaran dasar yang menentukan bagaimana hubungan internal harus diatur. Sehubungan dengan perpajakan, baik Partnership dan LLP melaporkan pendapatan atau kerugian bisnis atas pengembalian pajak pribadi mereka. ${ }^{32}$

\section{Perbandingan Bentuk Hukum Persekutuan di Indonesia dan Malaysia Menurut Undang-Undang Tiap Negara}

\footnotetext{
${ }^{27}$ Zuhairah Ariff Abd Ghadas dan Engku Rabiah Adawiah Engku Ali, Op.Cit., 301.

${ }^{28}$ Limited Liability Partnership Act s. 23 (2).

29 Mohammad Rizal Salim, "LIMITED LIABILITY PARTNERSHIP IN MALAYSIA: A CORPORATE GOVERNANCE PERSPECTIVE”, International Company and Commercial Law Review 12, no. 2 (2019): 421$427,423$.

${ }^{30}$ LLP Act s.6.

${ }^{31}$ LLP Act s.9.

${ }^{32}$ Zuhairah Ariff Abd Ghadas dan Engku Rabiah Adawiah Engku Ali, Op.Cit., 303.
} 
Bentuk hukum perusahaan persekutuan di Indonesia dan Malaysia memiliki perbedaan. Hal tersebut tidak terlepas dari perbedaan sistem hukum yang dianut oleh masing-masing negara. ${ }^{33}$ Negara Indonesia membawa hukum yang berasal dari Belanda, hal tersebut terjadi karena Indonesia merupakan negara bekas jajahan Belanda. ${ }^{34}$ Hukum perdatanya sampai saat ini masih menggunakan KUHPerdata yang merupakan peninggalan dari Belanda. Pengaruh Belanda yang memiliki sistem hukum Civil Law ${ }^{35}$ membuat Indonesia membagi antara hukum publik dan hukum privat namun tetap masih berada dalam satu atap peradilan. ${ }^{36}$ Malaysia, merupakan negara bekas jajahan Inggris dimana Malaysia tetap mempertahankan tradisi hukum kebiasaan Inggris yakni Common Law dan merupakan salah satu negara dari sekian banyak dari anggota negara-negara persemakmuran Inggris. ${ }^{37}$

Berikut ini merupakan tabel perbandingan antara perusahaan persekutuan di Indonesia dan Malaysia berdasarkan peraturan yang berlaku di negara masing-masing. Pengaturan perusahaan persekutuan di Indonesia menggunakan peraturan yang diatur di dalam KUHPer dan KUHD sedangkan perusahaan persekutuan di Malaysia menggunakan Partnership Act 1961 dan Limited Liability Partnership Act 2012. ${ }^{38}$

Tabel 1. Perbandingan Perusahaan Persekutuan di Indonesia dan Malaysia

\begin{tabular}{|l|l|}
\hline INDONESIA & Pengertian \\
Persekutuan Perdata: Suatu perjanjian dimana dua orang atau lebih \\
mengikatkan diri untuk sesuatu ke dalam perserikatan dengan maksud \\
membagi keuntungan atau kemanfaatan yang diperolehnya. (Pasal 1618 \\
KUHPer) \\
Firma: Tiap-tiap perserikatan yang didirikan oleh dua orang atau lebih untuk \\
menjalankan perusahaan dengan nama bersama. (Pasal 16 KUHD) \\
CV: Persekutuan Firma yang mempunyai satu atau beberapa orang sekutu \\
sekunder \\
Dasar Hukum \\
Persekutuan Perdata: diatur dalam Pasal 1618-1652 BW. \\
Firma: diatur dalam KUHD pada Pasal 16-35. \\
CV: diatur secara khusus dalam Pasal 19-21 KUHD. \\
Pendirian \\
Persekutuan Perdata: didirikan berdasarkan perjanjian dan tidak \\
mengharuskan adanya syarat tertulis. (Pasal 22, Pasal 23 dan Pasal 28 \\
KUHD) \\
Firma: didirikan dengan akta otentik dan di daftarkan ke kepaniteraan \\
Pengadilan Negeri dan diumumkan melalui Berita Negara. \\
CV: didirikan melalui pembuatan suatu perjanjian pendirian karena \\
\hline
\end{tabular}

\footnotetext{
${ }^{33}$ Wimmy Haliim, "DEMOKRASI DELIBERATIF INDONESIA : KONSEP PARTISIPASI MASYARAKAT DALAM MEMBENTUK DEMOKRASI DAN HUKUM YANG RESPONSIF," Jurnal Masyarakat Indonesia 42, no. 1 (2016): 19-30, 20.

${ }^{34}$ Ahmad Yani, "SISTEM PEMERINTAHAN INDONESIA: PENDEKATAN TEORI DAN PRAKTEK KONSTITUSI UNDANG-UNDANG DASAR 1945,” Jurnal Ilmiah Kebijakan Hukum 12, no. 2 (2018): 119135, 130, DOI: 10.30641/kebijakan.2018.V12.119-135.

35 Joseph Dainow, "THE CIVIL LAW AND THE COMMON LAW: SOME POINTS OF COMPARISON," The American Journal of Comparative Law 15, no. 3 (1966): 419-435, 419, DOI: 10.2307/838275.

36 Elsa Faleeda, "Perbandingan Struktur Sistem Hukum Malaysia dan Indonesia" http://syariah.uinmalang.ac.id/index.php/komunitas/blog-fakultas/entry/perbandingan-struktur-sistem-hukum-malaysia-danindonesia, diakses 27 Mei 2020.

37 Ibid.

${ }^{38}$ Ngau Duo Seng et al., "DETERMINANTS CONTRIBUTING TO THE PRIMARY MARKET SPREAD OF SECURITIZATION IN MALAYSIA,” International Journal of Innovation, Creativity and Change 11, no. 12 (2020): 137-148.
} 
melibatkan lebih dari satu orang dan selanjutnya pengusaha harus mendaftarkan CV pada Departemen Perindustrian dan Perdagangan sesuai dengan Peraturan Perundang-undangan yang berlaku.

Tanggung Jawab

Persekutuan Perdata: Apabila seorang mengadakan suatu hubungan hukum dengan pihak ketiga, maka sekutu yang bersangkutan saja yang bertanggung jawab atas perbuatan hukum yang dilakukan dengan pihak ketiga itu, walaupun dia mengatakan bahwa perbuatannya untuk kepentingan sekutu, kecuali jika sekutu-sekutu lainnya memang nyata-nyata memberikan kuasa atas perbuatannya itu. (Pasal 1642, Pasal 1644 dan Pasal 1639 KUHPerdata) Firma: Setiap sekutu dalam Firma dapat melakukan perikatan atau hubungan hukum dengan pihak ketiga untuk dan atas nama perseroan, tanpa perlu adanya surat kuasa khusus dari sekutu lainnya, jadi semua sekutu bertanggung jawab secara tanggung renteng. (Pasal 21 KUHD)

$\mathrm{CV}$ : tanggung jawab sekutu aktif yang disamping menanamkan modal ke dalam perusahaan juga bertugas mengurus perusahaan, sedangkan sekutu pasif yang hanya memasukkan modal saja dan tidak terlibat atas pengurusan perusahaan. Akibatnya, Sekutu aktif bertanggung jawab tidak hanya atas kekayaan CV, tetapi juga kekayaan pribadi jika diperlukan. Namun, untuk sekutu pasif hanya bertanggung jawab sebatas modal yang dimasukkan ke dalam CV, apabila ikut melakukan pengurusan. (Pasal 1619 KUHPer)

\section{Modal}

Persekutuan Perdata: Modal dalam Persekutuan Perdata terdapat pengaturannya di dalam Pasal 1619 BW, yaitu uang, barang dan tenaga/kerajinan.

Firma dan CV: Tiap-tiap sekutu dalam firma diwajibkan memasukkan dalam kas persekutuan modal berupa uang, benda atau tenaga. Pemasukkan ini disebut dengan inbreng. (Pasal 1619 KUHPer)

\section{Sekutu}

Persekutuan Perdata: Memiliki 2 macam cara mengangkat sekutu, yakni Statuter dan Mandater

Firma: hanya terdapat satu macam sekutu, yaitu sekutu Komplementer.

CV: Memiliki 2 jenis sekutu, yakni Sekutu aktif (Komplementer) dan Sekutu Pasif (Komanditer)

\section{Pembubaran}

Persekutuan Perdata: berakhir apabila (1646 BW): Waktu yang ditentukan untuk bekerja telah lampau, barang yang menjadi objek usaha musnah atau usaha yang menjadi tugas pokok selesai, seorang atau lebih sekutu mengundurkan diri atau meninggal dunia atau ditaruh di bawah pengampuan atau pailit, merupakan kehendak dari beberapa atau seorang sekutu untuk mengakhiri persekutuan

Firma: berakhir/bubar apabila (1646 BW): Waktu yang telah ditentukan untuk bekerja telah lampau, barang yang menjadi objek usaha musnah atau usaha yang menjadi tugas pokok selesai, seorang atau lebih sekutu mengundurkan diri atau meninggal dunia atau ditaruh di bawah pengampuan atau pailit, merupakan kehendak dari beberapa atau seorang sekutu untuk mengakhiri persekutuan.

$\mathrm{CV}$ : berakhirnya $\mathrm{CV}$ dapat dikatakan sama dengan berakhirnya persekutuan Firma 


\begin{tabular}{|c|c|}
\hline MALAYSIA & 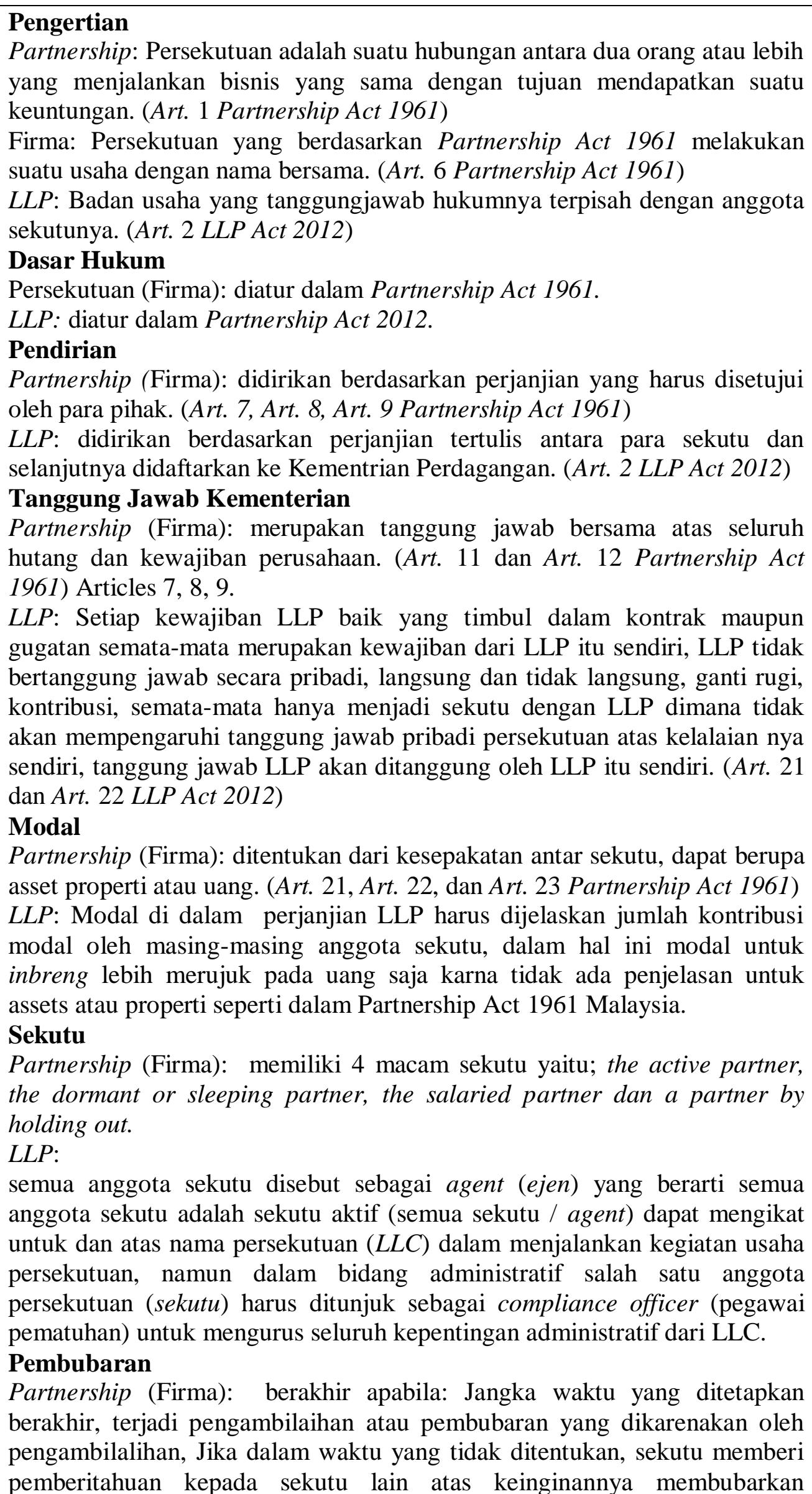 \\
\hline
\end{tabular}




\section{persekekutuan. (Art. 34 Partnership Act 1961)}

LLP: ada tiga hal yang dapat terjadi dalam pembubarannya yaitu Windingup, Dissolution, Striking-off yang mana dalam bahasa malaysia disebut Penggulungan, Pembubaran dan Pemotongan (Pasal 49,50,51 LLC ACT) yang mana pembubaran ini dapat dilakukan oleh Pengadilan (Mahkamah), pembubaran secara sukarela dari persekutuan ( $L L C)$ dan oleh Ketua Pegawai Eksekutif Suruhanjaya).

\section{Kesimpulan}

Berdasarkan hasil pembahasan dan penelitian terhadap masalah yang diteliti negara Malaysia merupakan negara common law yang membagi beberapa Business Entity yang ada di negara nya menjadi 5 bagian, salah satunya adalah Partnership atau Persekutuan atau Perkongsian dan Limited Liability Partnership di Malaysia. Partnership mengatur mengenai perusahaan secara tradisional dengan ingin mendapatkan laba atau keuntungan. Sedangkan di dalam LLP ini sedikit berbeda namun sebenarnya masih merujuk kepada aturan mengenai Partnership itu sendiri sebagai dasar untuk melaksanakan kegiatannya dengan menggabungkannya dengan konsep company. Terdapat pula perbedaan antara bentuk dan peraturan yang mengatur perusahaan persekutuan Indonesia dengan perusahaan persekutuan Malaysia. Undang-Undang yang digunakan pun berbeda untuk keduanya, Partnership diatur dalam Partnership Act 1961 sedangkan untuk Limited Liability Partnership diatur dalam Limited Liability Act 2012. Di dalam aturan tersebut terdapat beberapa perbedaan dimana dalam LLP ini lebih mengatur perusahaan sebagai suatu subjek sendiri dan merupakan gabungan dari Partnership dengan perusahaan. Terhadap Undang-Undang atau Act yang berlaku di Malaysia sudah secara rinci menjelaskan mengenai aturan perusahaan khususnya perusahaan persekutuan yang berlaku di negara tersebut. Bentuk perusahaan persekutuan Indonesia terdiri dari persekutuan perdata, firma dan $\mathrm{CV}$ yang masing-masing diatur di dalam KUHPer dan KUHD sedangkan bentuk perusahaan persekutuan Malaysia terdiri dari partnership yang diatur di dalam Partnership Act 1961 yang kemudian dibentuk suatu jenis usaha yang baru yakni Limited Liability Partnership yang merupakan gabungan dari jenis usaha partnership dan company dimana pengaturannya berada dalam Limited Liability Partnership Act 2012.

Dalam hal ini penulis akan menyarankan agar Pemerintah hendaknya membuat sebuah undang-undang yang mengatur mengenai bentuk usaha Persekutuan ini lebih khusus dalam peraturan yang berbeda agar dapat mudah dipahami oleh pelaku usaha seperti peraturan yang berlaku di negara Malaysia, karena di Indonesia peraturan mengenai bentuk perusahaan persekutuan, firma dan CV masih tersebar di dalam KUHPer dan KUHD. Peraturan mengenai partnership dan LLP di Malaysia dibuat dalam peraturan yang berbeda sehingga pelaku usaha dapat lebih mudah memahami hal-hal yang berhubungan dengan bentuk dan kegiatan usaha tersebut. 


\section{A. Jurnal}

\section{DAFTAR PUSTAKA}

Budianto, Agus. "PEMBAHARUAN KITAB HUKUM DAGANG INDONESIA : ANTARA KODIFIKASI, KOMPILASI DAN KONSOLIDASI." Jurnal Ilmu Syari'ah Dan Hukum “Asy-Syir'ah" 47, no. 2, 2013: 703-725.

Carayannis, Elias G., Ruslan Rakhmatullin. "THE QUADRUPLE/QUINTUPLE INNOVATION HELIXES AND SMART SPECIALISATION STRATEGIES FOR SUSTAINABLE AND INCLUSIVE GROWTH IN EUROPE AND BEYOND." Journal of the Knowledge Economy 5, no. 2, 2014: 212-239, DOI: 10.1007/s13132-014-0185-8.

Dainow, Joseph. "THE CIVIL LAW AND THE COMMON LAW: SOME POINTS OF COMPARISON." The American Journal of Comparative Law 15, no. 3, 1966: 419-435, DOI: $10.2307 / 838275$.

Davidsson, Per. "ENTREPRENEURIAL OPPORTUNITIES AND THE ENTREPRENEURSHIP NEXUS: A RE-CONCEPTUALIZATION.” Journal of Business Venturing 30, no. 5, 2015: 674-695. DOI: 10.1016/j.jbusvent.2015.01.002. Dharnayanti, Ni Made Pratiwi., Usfunan, Yohanes., Sarjana, I Made. "HUBUNGAN HUKUM PERUSAHAAN INDUK BERBENTUK PERSEROAN TERBATAS DENGAN ANAK PERUSAHAAN BERBENTUK PERSEKUTUAN KOMANDITER." Acta Comitas 2, no. 1, 2017: 66-74, DOI: 10.24843/AC.2017.v02.i01.p06.

Edy Susanto, Marhamah. Summary For Policymakers In Climate Change 2013 - The Physical Science Basis, edited by Intergovernmental Panel on Climate Change. Cambridge: Cambridge University Press, 2019, DOI: 10.1017/CBO9781107415324.004.

Haliim, Wimmy. "DEMOKRASI DELIBERATIF INDONESIA : KONSEP PARTISIPASI MASYARAKAT DALAM MEMBENTUK DEMOKRASI DAN HUKUM YANG RESPONSIF.” Jurnal Masyarakat Indonesia 42, no. 1, 2016: 19-30.

Jaswadi. "PENERAPAN GOOD GOVERNANCE PADA PERUSAHAAN SKALA KECIL DAN MENENGAH NON GO PUBLIC." Journal of Research and Applications: Accounting and Management 1, no. 3, 2016: 236-248, DOI: 10.18382/jraam.v1i3.39.

Kelly, David., Hammer, Ruby., Hendy, John. "PARTNERSHIP LAW.” Business Law 69, no. 3, 2017: 323-352, DOI: 10.4324/9781315726205-17.

Manikandan, K. S., Ramachandran, J. "BEYOND INSTITUTIONAL VOIDS: BUSINESS GROUPS, INCOMPLETE MARKETS, AND ORGANIZATIONAL FORM.” Strategic Management Journal 36, no. 4, 2015: 598-617, DOI: 10.1002/smj.2226.

Rahman, N. A., Z. A. Abd Ghadas, K. Salleh, and H. M. Ab Rahman. "LIMITED LIABILITY PARTNERSHIP (LLP@PLT): NEW BUSINESS VEHICLE FOR THE MALAYSIAN LEGAL AND ACCOUNTING PRIVATE PRACTICE." Pertanika Journal of Social Sciences and Humanities 23, no. 11, 2015: 211-218.

Ramadhan, Muhammad, Laily, Yunial. "ANALISIS HUKUM PERJANJIAN KERJA SAMA INVESTASI ANTARA PERSEKUTUAN KOMANDITER DAN INVESTOR ASING MENURUT HUKUM INVESTASI DI INDONESIA.” Jurnal Ilmu Hukum 5, no. 1, 2018: 771-780. DOI: 10.5281/zenodo.1684252.

Seng, Ngau Duo, et.al. "DETERMINANTS CONTRIBUTING TO THE PRIMARY MARKET SPREAD OF SECURITIZATION IN MALAYSIA.” International Journal of Innovation, Creativity and Change 11, no. 12, 2020: 137-148.

Simorangkir, Julius Caesar Transon. "TANGGUNG JAWAB SEKUTU MAATSCHAP TERHADAP PIHAK KE 3 DALAM SUATU PERJANJIAN KONSORSIUM TERKAIT BUBARNYA MAATSCHAP ATAS KEHENDAK PARA SEKUTU (KASUS PERJANJIAN KONSORSIUM ANTARA PT AGRO BINTANG DHARMA NUSANTARA DENGAN PEMERINTAH DAERAH BALIKPAPAN, BONTANG." Fiat Justisia: Jurnal Ilmu Hukum 9, no. 2, 2016: 233-255, DOI: 
10.25041/fiatjustisia.v9no2.599.

Yani, Ahmad. "SISTEM PEMERINTAHAN INDONESIA: PENDEKATAN TEORI DAN PRAKTEK KONSTITUSI UNDANG-UNDANG DASAR 1945.” Jurnal Ilmiah Kebijakan Hukum 12, no. 2, 2018: 119-135, DOI: 10.30641/kebijakan.2018.V12.119135.

Zakhina, Ina., Safa'at, Rachmad., Istislam. "SUMMARY FOR POLICYMAKERS.” EDITED BY INTERGOVERNMENTAL PANEL ON CLIMATE CHANGe". Climate Change 2013 - The Physical Science Basis 8, no. 9, 2016: 1-30, DOI: 10.1017/CBO9781107415324.004.

\section{B. Buku}

Dewi, Yetty Komalasari. Hukum Persekutuan di Indonesia Teori dan Kasus. Depok: Badan Penerbit Fakultas Hukum Universitas Indonesia, 2017.

Muhammad, Abdulkadir. Hukum Perusahaan Indonesia. Bandung: Citra Aditya Bakti, 2002. Nasution, Johan. Metode Penelitian Hukum. Bandung: Mandar Maju, 2008.

Prasetya, Rudhi. Maatschap, Firma, dan Persekutuan Komanditer. Bandung: Citra Aditya Bakti, 2002.

Purwosutjipto, HMN. Pengertian Pokok Hukum Dagang Indonesia: Bentuk-Bentuk Perusahaan. Jakarta: Djambatan, 1987.

\section{Internet}

http://syariah.uin-malang.ac.id/index.php/komunitas/blog-fakultas/entry/perbandinganstruktur-sistem-hukum-malaysia-dan-indonesia, diakses pada 23 Februari 2020.

www.paulhypepage.my/what-are-the-5-types-of-business-entity-in-malaysia/, diakses pada 23 Februari 2020. 
